\title{
Die Sonnenstadt
}

\author{
Erhard Taverna
}

Wer vom oberen Tibertal ausgehend von San Sepolcro über den Monte Casale und über die Mondalpen noch weiter nordwärts wandert, wird nach einigen Tagen am Horizont zwei felsige, abgeflachte Berge, den Simone und den Simoncello, erblicken.

Trotz Markierungen und der Wanderkarte «Alta Val Marecchia» sind die Wege durch die ausgedehnten Wälder im Grenzgebiet von Toskana, Marche und Romagna, schwierig zu finden. Von morgens bis abends keine Begegnung mit Wanderern, kein Motorenlärm, nur rauschende Bäche und Wasserfälle, Vögel, Grillen und der Wind. Im Eichenlaub des Vorjahres rascheln die Eidechsen, und viele Kuckucksmännchen sind unermüdlich auf Nestsuche. Das weite Land ist hügelig und fast menschenleer, die kleinen Kirchen und abgelegenen Ortschaften liegen wie Inseln im fernen Hinterland der Adriaküste. Die Königinnen der Düfte sind blühende Robinien, Zimtrosen, Geissblatt und Ginster. Wo die Buchen, Eichen und Eschen in Hecken und Lichtungen übergehen, blühen Milchsterne, Salbei und Mohn. Überall schiesst das Knabenkraut in die Höhe. Ragwurzblüten locken als perfekte Fliegen-, Hummeln- und Bienenattrappen. Mauersegler durchsicheln den blauen Himmel, Nachtigall und Pirol mischen mit im lauten Zwitscherkonzert der Mönchsgrasmücken.

Wer die Ursprünge des Apennins studieren will, kann beim Aufstieg zum Sasso Simone Fossilien suchen oder Mineralien wie Kalzit, Mangan und Pyrit. Wasser und Kälte haben aus der Hochebene am Fuss der Felsen tiefe Spalten herausgespült. Eine aufgesprungene, trockene Lehmschicht überzieht die steilen Grate wie eine Reptilienhaut.

Einst führte eine Strasse durch diese Mondlandschaft. Von ihr sind nur noch die Kalkplatten des letzten Wegstücks zum Plateau des Felshügels erhalten. Cosimo I, mit 18 Jahren Grossherzog von Florenz, plante 1554 erstmals eine Festungsstadt an dem strategisch wichtigen, aber weit abgelegenen Ort. Ein Vorposten im vergeblichen Ringen um einen Zugang an die Adria, gebaut nach den Prinzipien der Ordnung, der Vernunft und der göttlichen Weisheit. Eine Idealstadt der Renaissance nach den Machtrezepten eines Niccolò Machiavelli und eines geistigen Gegenspielers wie Tommaso Campanella,

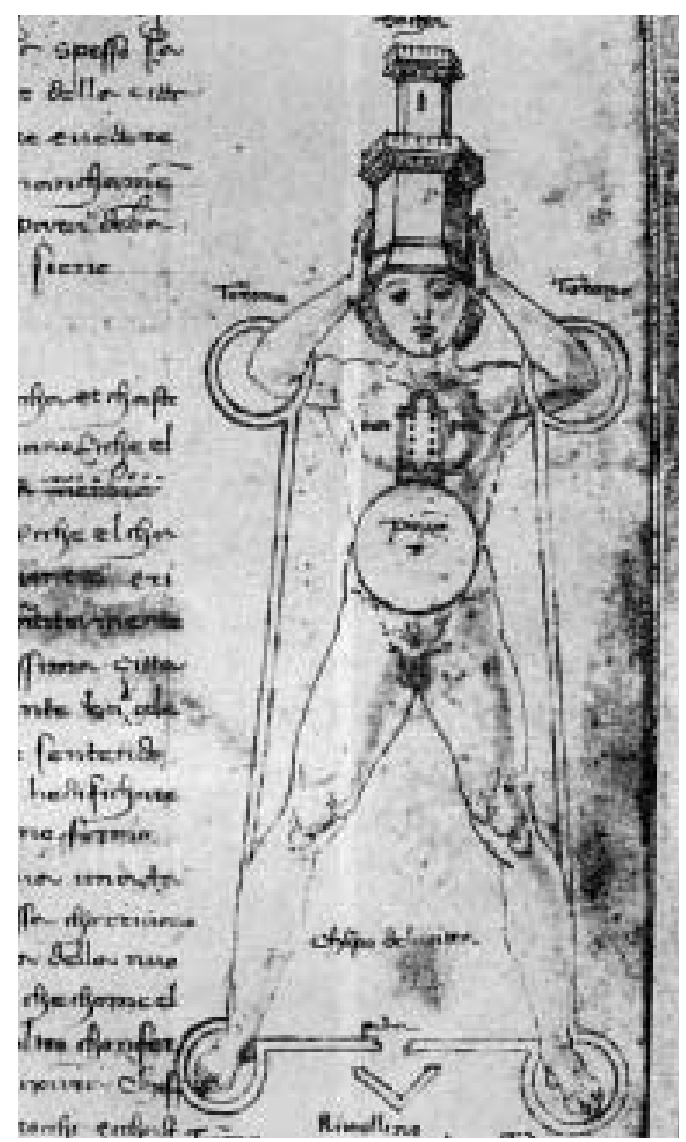

der in seiner Utopie der «Civitas solis» den idealen, kommunistischen Staat konzipierte. Beide verbindet das zeitgemässe Vorbild des Universalmenschen, der die göttliche Harmonie in den Gesetzen der Natur entdeckt und in den Proportionen des menschlichen Körpers zum Ausdruck bringt. Die zahlreichen Künstlergenies jener Zeit, wie Leonardo da Vinci oder Francesco di Giorgio Martini, zeichnen Festungspläne und Stadtgeometrien wie menschliche Gliedmassen. Das Sonnensymbol in den zahlreichen Stadtwappen der Medicis vereinigt die wiederbelebte neuplatonische Philosophie mit der florentinischen Aristokratie. Der Fürst ist das Haupt der harmonischen Gesellschaft.

Campanella (1568-1639), der Sozialutopist und Dominikaner, überlässt einem genuesischen Admiral die Beschreibung der idealen Sonnenstadt «auf einem gewaltigen Hügel mit sieben bemalten Mauern und vier Toren». Die Malereien lehren das ganze Wissen der Zeit, wobei die Erziehung für beide Geschlechter eine zentrale 
Rolle spielt. Militärdienst, Viehzucht und Ackerbau sind Pflicht für Mann und Frau. Seine Pädagogik und Sittenlehre lesen sich wie eine Vorstufe von Pestalozzis Forderung einer Erziehung von Kopf, Hand und Herz. Eine Hierarchie der Besten regiert zum Wohle aller Bürger und Bürgerinnen. Die strengen Reproduktionsgesetze der astrologisch gelenkten Medizin vereinigen Eugenik mit staatlich geregelter Promiskuität. Kleidervorschriften, Leibesertüchtigung und Ernährungsregeln garantieren ein langes Leben. Sein Prinzip der ausgleichenden Harmonielehre gründet auf Können, Wissen und Wollen. Auch die Sonne der Medici erhebt den Anspruch mit Macht, Weisheit und Liebe eine naturgesetzliche Ordnung mit Herrschaft zu verbinden.

Der Wind streicht über die ausgedehnte Wiesenfläche auf dem Berg. Ein Graben lässt eine Zisterne ahnen. Von den rechtwinkligen Strassen und fabrikähnlichen Behausungen früherer Veduten und Skizzen ist nichts mehr zu sehen. Die Mauern sind versunken, wo der Palast stand, blüht der gelbe Hahnenfuss unter Eschen und Kastanien. Die Abendsonne vergoldet das weite
Schutzgebiet im Norden und Osten, durch das der Abstieg nach Carpegna führt. Hauptsitz im Herrschaftsgebiet der Montefeltro, deren Nachkommen noch heute in Rom leben. Nicht an deren Widerstand ist das Projekt gescheitert. Es kam nie recht vom Fleck, denn wer wollte schon in dieser Einöde leben? Und dann kam die kleine Eiszeit mit harten Wintern und schlechten Ernten. Die Türme zerfielen, boten Nischen für Falken und Mauerdohlen. Die Macht fand neue Häuser, während der Wald sich ausdehnte.

Die Schatten werden länger, und die vielen Stimmen in den Bäumen verstummen. Bald werden Sterne funkeln und Frösche quaken. Wie die Nacht dem Tag folgt der Zerfall dem Aufbau aller Sonnenstädte. Was von denen übrigbleibt, leuchtet nachtblau und vergoldet in der Mosaikkuppel der Basilika von San Vitale. Dort, im byzantinischen Ravenna, stützen die vier Erzengel mit emporgereckten Händen den Sternenhimmel mit dem kosmischen Lamm. Unter ihnen ranken sich die Blattgewinde und Blumenranken mit den Vögeln, den Fischen und den Tieren des Waldes. Sie sind die wahren Bewohner der Stadt. 